Research Article

\title{
Simultaneous Operations of Pregrouting and Shaft Drilling in Shaft Construction
}

\author{
Zhipeng Xu $\mathbb{D},,^{1,2}$ Xuhai Feng $\mathbb{D},{ }^{3}$ Shengsheng Li $\mathbb{D},{ }^{3}$ Liming Fan $\mathbb{D},{ }^{4}$ and Changwu Liu $\mathbb{D}^{1,2}$ \\ ${ }^{1}$ College of Water Resource and Hydropower, Sichuan University, Chengdu, Sichuan 610065, China \\ ${ }^{2}$ State Key Laboratory of Hydraulics and Mountain River Engineering, Sichuan University, Chengdu, Sichuan 610065, China \\ ${ }^{3}$ China Coal Technology \& Engineering Crop, Beijing 100013, China \\ ${ }^{4}$ CCDC Drilling \& Production Technology Research Institute, Chengdu, Sichuan 610051, China
}

Correspondence should be addressed to Zhipeng Xu; zpxu2018@126.com and Changwu Liu; liuchangwu@scu.edu.cn

Received 21 February 2020; Revised 27 September 2020; Accepted 17 October 2020; Published 9 December 2020

Academic Editor: Weerachart Tangchirapat

Copyright $\odot 2020$ Zhipeng Xu et al. This is an open access article distributed under the Creative Commons Attribution License, which permits unrestricted use, distribution, and reproduction in any medium, provided the original work is properly cited.

\begin{abstract}
In shaft construction, conducting shaft drilling and pregrouting simultaneously is expected to speed up the sinking rate and save the cost. Reasonable determination of the spatial locations of the drilled shaft and grouting holes and proper defining of the start time of each construction work are the crucial techniques. To smoothly execute the simultaneous operations, the bedrock to be grouted is divided into two sections. The upper bedrock is injected first using straight grouting holes to act as a tight cover to protect shaft drilling. Then, the lower formations are grouted using $S$-shaped grouting holes, which are performed simultaneously with shaft drilling. The construction time of simultaneous operations of pregrouting for the lower bedrock using $S$-shaped holes and shaft drilling is the saved time. The main technical challenges include the stability of grouting holes and safety of shaft walls, as well as the disposal of the contaminative waste drilling mud. The stability of grouting holes which might affect by the shaft drillinginduced ground vibration could be evaluated according to the penetration of ground vibration caused by TBM tunnelling. If the grouting hole is in the range of ground vibration, protective measures including casing and ground improvement should be utilized to ensure the stability of grouting holes. The stability of unlined walls of the drilled shaft caused by the increased groundwater pressure can be achieved by a tight cover between the drilled shaft and pregrouting holes. The thickness of the cover is actually the length of the straight holes. The cover should have sufficient thickness and impermeability, which can considerably reduce or even completely stop the increased groundwater pressure in vicinity of the drilled shaft. The thickness and permeability of the cover could be determined using Maag's solution for penetration of grouts in porous media. On the other hand, the waste drilling mud with proper modifications can be reutilized to prepare clay-cement-like grouts, which could provide an eco-friendly and cheap solution to harmlessly treat the huge volume of waste drilling mud. The properties of waste drilling mud and behaviors of grouts prepared using the waste mud should be experimentally investigated before reutilization, owing to uncertainties of geology in various cases. The construction time using the simultaneous operation method is just about $60 \%$ of that of the traditional excavation method, and the low value of measured residual water inflow shows the reliability of reusing the waste drilling mud as grouting materials. The proposed method could virtually improve the shaft sinking rate and save the construction cost. The principles developed for these technical challenges have been proved to be applicable in practices, which are believed to strongly support the applicability of this new method in other cases.
\end{abstract}

\section{Introduction}

Vertical shafts are virtually considered as the most important accesses of deep mining in the plain area, which always provide services for underground operations such as ventilation, transportation of workers and ores, communications, and power supply $[1,2]$. It is reported that although the construction quantity of shaft sinking only accounts for less than $7 \%$ of the entire of the coal mine, the fraction of construction time of shaft sinking reaches up to $40 \% \sim 60 \%[2,3]$. The penetration rate of shaft sinking not only determines the opening of the mine but also affects the 
cost considerably. Therefore, speeding up the sinking rate is reckoned to be the most cost-effective way to save both the cost and time [4-7]. The penetration rate of shaft sinking usually depends on the excavation methods and the specific depth of the mine [2]. In the east plain region of China, the bedrock is often covered by alluviums with a thickness of around $500 \mathrm{~m} \sim 600 \mathrm{~m}$. To minimize the risk of groundwater inflow during excavating in upper alluviums formations, shaft drilling is considered as a safer construction method for shaft sinking in upper alluviums to replace the artificial ground freezing method, while pregrouting from the surface followed by the conventional drilling and blasting method is believed to be the most reliable method for shaft excavation in the bedrock $[3,5,8,9]$. Traditionally, the operations are conducted successively to avoid potential interferences which might cause serious safety concerns. In order to further shorten the construction time and reduce the cost, the shaft drilling is attempted to be conducted simultaneously with pregrouting.

However, conducting independent operations simultaneously may adversely impact the safety of another operation [10]. Specifically, the stability of grouting holes might be deteriorated by the shaft drilling-induced ground vibration, while the safety of the drilled shaft wall may also be damaged by the over-penetrated grouting materials and increased groundwater pressure. Furthermore, how to harmlessly treat the contaminative waste drilling mud becomes another knotty problem. Drilling or tunnelling-induced ground vibration might cause stability issues associated with both the wellbore and structures in the vicinity $[11,12]$. During drilling, the cutting bit/formations and drilling string/borehole interactions will inevitably cause some vibrations. Bailey and Finnie [13, 14] experimentally studied the measurement approach of axial force, torque, and axial and rotational motions on the top of drillstring and proposed relating analytical solutions for both the longitudinal and torsional vibrations. Kyllingstad and Halsey [15] and Brett [16] investigated the stick-slip vibrations generated at the interface between bit and formations. Ibrahim et al. [12] presented mathematical models of longitudinal and torsional vibrations as well as the model coupling the two vibrations to help understand the entire force of drill-string and the displacement. Itakura et al. [17] and Liu et al. [18, 19] reported the dependence of vibration on the rock properties. They found that the measured vibrations can be employed to estimate the downhole geological conditions. Ainalis et al. [11] evaluated the ground vibration produced by various man-made sources including explosive blasting and traffic loading. The dynamic effect of ground vibration on above structures and underground facilities depends on not only the type of excitation but also the damping properties of the medium [20]. The amplitude of ground vibration generally decreases with increasing the distance from the source. Tavasoli and Ghazavi [21] concluded that the wave propagation will gradually terminate if the distance exceeds the range of about 20 times the pile diameter by field testing and numerical analysis. A review of literature reveals that the drilling operation does produce some seismic wave and thus induce ground vibration in vicinity regions. But the influential range for the effect of ground vibration needs to be estimated in accordance with specific conditions, and the stability of grouting holes under the interference of induced ground vibration should be appropriately assessed.

Another challenging concern is the stability of the drilled shaft wall, which may be caused by the over-penetrated grouts and increased groundwater pressure during the simultaneous operations. As known, excessive penetration of grouts might be inevitable owing to the complexity and uncertainty of geology [22]. In practices, over-penetrated grouts injected from a point with about 500-800 $\mathrm{m}$ depth can be occasionally observed on the surface. This might be attributed to the geological structures and potential fractured zones. In most cases, the grouting pressure and grouting-induced increase of groundwater pressure will be gradually attenuated. In contrast, the grouting-induced increase of groundwater pressure has the greater influential range than that of grouting pressure. If the drilled shaft is still in the coverage of increased groundwater pressure, the stability of the drilled shaft wall may be adversely affected. Therefore, the evolution of grouting-induced increase of groundwater pressure should be properly estimated and corresponding solutions should be identified in advance. On the other hand, the course of shaft drilling will produce a huge amount of contaminative waste drilling mud. The waste drilling mud behaves as a mixture that usually consists of fine clay particles, water, and chemical additives in some specific conditions [23]. The chemical additives that might transfer pollutants to water or soils are the main source of pollution, and the degree of difficulty in solidification of the mud poses another way to contaminate the soil system [24]. In general, technical methods available for treatment of the waste drilling mud include burial in pits, landfill, reinjection, solid-liquid separation, stabilization/solidification, thermal treatment, and bioremediation techniques which introduce microorganisms and relevant enzymes to biologically degrade the waste drilling mud into nontoxic residues [25]. Based on local conditions, resource recycling of the waste mud as renewable construction materials might be the most promising and environmental-friendly alternative to treat these waste drilling mud.

As of now, there are extremely few literatures that investigated the technical concerns and problems encountered in the simultaneous operations of pregrouting and shaft drilling. The purpose of this paper is to focus on evaluations of the technical challenges emerged in the process of simultaneous operations. Both the stability of grouting holes and the shaft wall and the reuse of the drilling wastes as grouting materials are discussed, and corresponding solutions are proposed. The results reveal that proposed solutions are proved to be applicable and reliable in shaft sinking. The sinking rate can be considerably improved by simultaneous operations.

\section{Project Background and Geological Setting}

The coal mine involved in this investigation is situated in the northern part of Anhui Province, as shown in Figure 1. The 


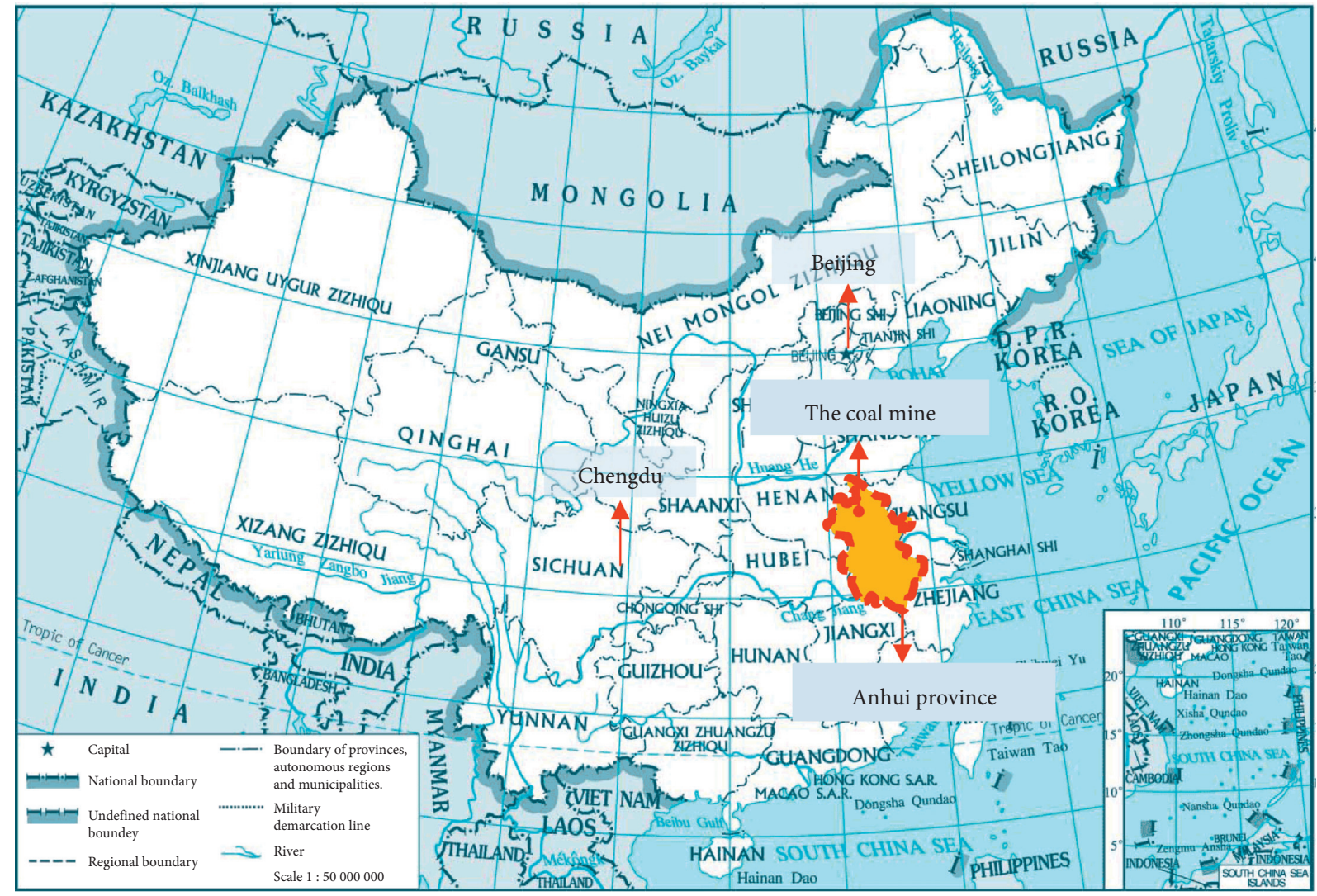

Figure 1: Location of the coal mine.

proved reserve of coal is up to about 855 million tons, while estimated recoverable reserve reaches around 406 million tons. It is designed with a mine capacity of 4 million tons per year and a service life of about 72.6 years. In this coalfield, the thickness of the upper alluvium formations varies from $312 \mathrm{~m}$ to $540 \mathrm{~m}$ beneath the surface. Therefore, four vertical shafts to be newly constructed are employed to serve the activities of deep underground mining. Designed parameters of shafts are illustrated in Table 1 . The waste shaft that will be used to transport coal gangue and other materials from underground roadways is selected as the case to be investigated in this work. The depth of the waste shaft is $1068 \mathrm{~m}$, and the excavated diameter is $6 \mathrm{~m}$. According to the hydrogeological survey, the estimated water inflow into the shaft will be up to $213 \mathrm{~m}^{3} / \mathrm{h}$. Considering the high risk of groundwater inflow, shaft drilling by the shaft boring machine (SBM) and pregrouting from the surface are predefined as the methods for shaft sinking.

Based on the site investigation, the minable coal-bearing strata include Shanxi and Shihezi formations of the Permian system $\left(P_{2}^{1}, P_{1}^{2}\right.$, and $\left.P_{1}^{1}\right)$, with a maximum depth of around $1000 \mathrm{~m}$. The lithology of the bedrock includes sandstones, siltstones, mudstones, and coal seams. The upper alluvium with the thickness of round $470 \mathrm{~m}$ mainly consists of cohesive soils, with ages from quaternary to tertiary. The bedrock includes limestone, sandstone, siltstone, mudstone, and unworkable coal layers with the age of carboniferous. It can be found that 4 water-bearing zones are located in the upper alluvium, whereas 3 water-bearing formations are developed in the bedrock. The coal layers, mudstone, and siltstone serve as the aquifuge that can almost cutoff the hydraulic connection with the water-bearing formations. The initial water table is about $15.7 \mathrm{~m}$ beneath the surface, and total thickness of the water-bearing strata is about $120.5 \mathrm{~m}$. Moreover, several fractured zones in the bedrock with a depth ranged from $590 \mathrm{~m}$ to $1089 \mathrm{~m}$ can be observed. What is worse, there are 3 faults developed in this coalfield and one fault intersects the waste shaft at a depth of around $1070 \mathrm{~m}$. Abundant groundwater storage and unstable ground conditions considerably increase the difficulty of shaft sinking.

\section{Implementation of Simultaneous Operations}

In construction management, the construction methods, techniques, and sequences are often considered as the key factors that affect the cost and quality control [26]. Rational selection of construction techniques and efficient arrangement of these construction sequences become the best way to reduce the cost and save construction time. The risk imposed by conducting multiple operations at the same time should be limited to the acceptable level associated with that of the execution of these operations individually [10].

Traditionally, pregrouting for the bedrock is conducted prior to the shaft drilling, as shown in Figure 2(a). After completion of the course of pregrouting, the shaft boring 
TABLe 1: Designed parameters of shafts.

\begin{tabular}{|c|c|c|c|c|}
\hline Parameter & Main shaft & Auxiliary shaft & Ventilating shaft & Waste shaft \\
\hline Designed excavated diameter & $7.3 \mathrm{~m}$ & $9.4 \mathrm{~m}$ & $8.5 \mathrm{~m}$ & $7.7 \mathrm{~m}$ \\
\hline Designed effective diameter & $6.4 \mathrm{~m}$ & $8.3 \mathrm{~m}$ & $7.5 \mathrm{~m}$ & $5.2 \mathrm{~m}$ \\
\hline Depth of the bottom & $993 \mathrm{~m}$ & $1015 \mathrm{~m}$ & $893 \mathrm{~m}$ & $1068 \mathrm{~m}$ \\
\hline Material of the shaft wall & \multicolumn{4}{|c|}{ Reinforced concrete for upper alluvium, plain concrete for the bedrock } \\
\hline Thickness of shaft wall in the bedrock & \multicolumn{4}{|c|}{$0.4 \mathrm{~m}$} \\
\hline Designed mining level 1 & \multicolumn{4}{|c|}{$-962 \mathrm{~m}$} \\
\hline Designed mining level 2 & \multicolumn{4}{|c|}{$-1150 \mathrm{~m}$} \\
\hline Selected special sinking method & Freezing + pregrouting & Freezing + pregrouting & Freezing + pregrouting & Drilling + pregrouting \\
\hline
\end{tabular}

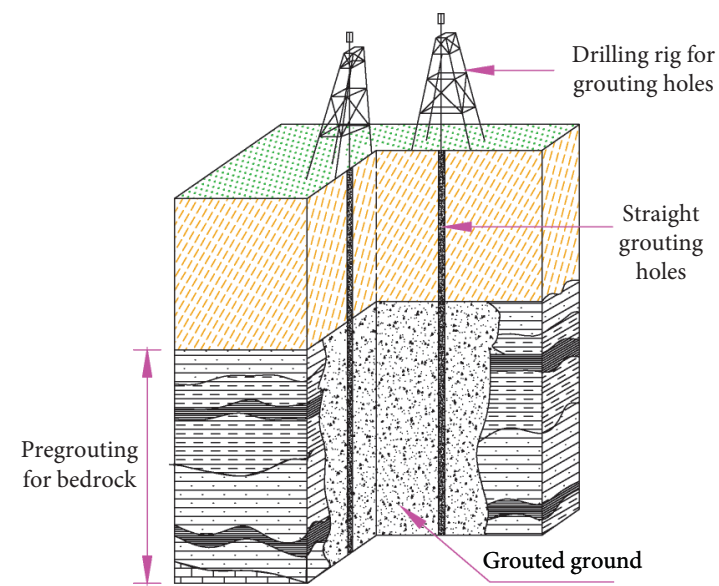

(a)

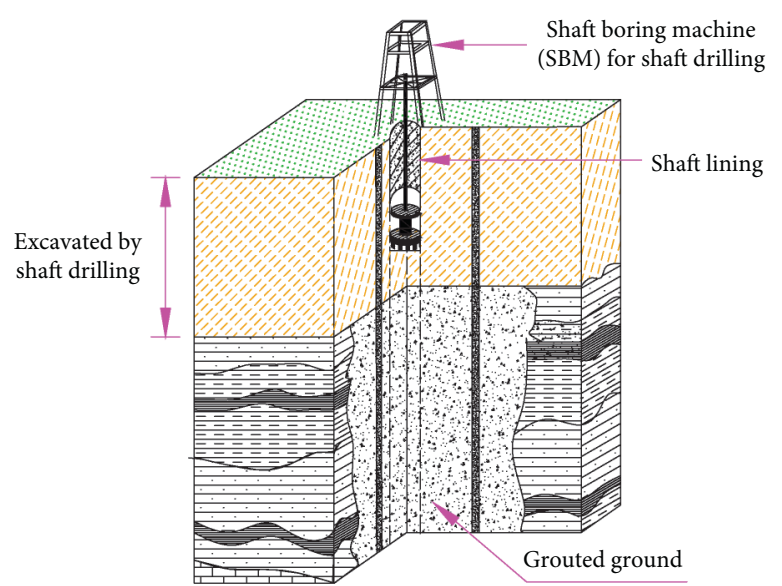

(b)

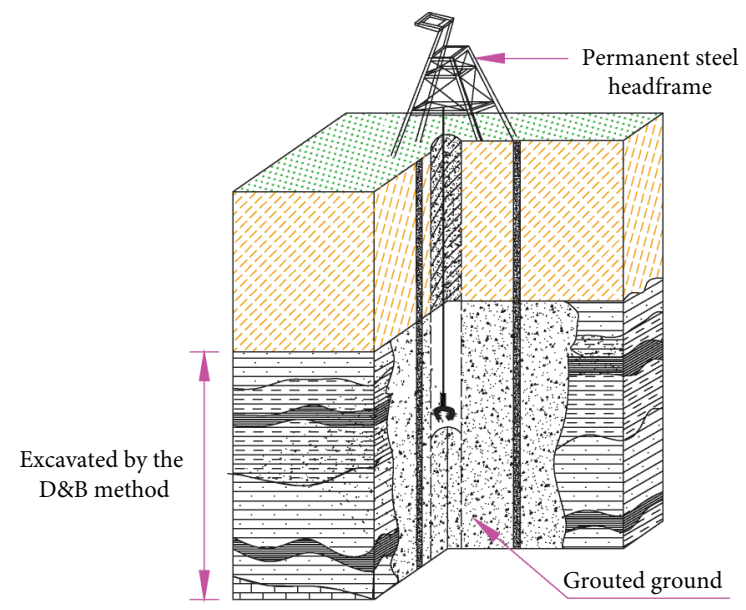

(c)

Figure 2: Traditional procedure for shaft sinking by pregrouting and shaft drilling. (a) Pregrouting from the surface is conducted first. (b) Shaft drilling. (c) Bedrock is excavated by the traditional D\&B method.

machine (SBM) is properly installed on the surface to perform the shaft drilling operation, as shown in Figure 2(b). When the operation of shaft drilling is finished, the permanent steel headframe is setup to perform the shaft excavation by the conventional drill-blast method in the bedrock, as shown in Figure 2(c). In this step-by-step procedure of shaft sinking, the total construction time is the sum of pregrouting time, shaft drilling time, and D\&B excavation time.

In order to speed up the sinking rate, efforts are devoted to conduct these operations at the same time. Accordingly, conducting the pregrouting operation and shaft shrilling simultaneously provides a possible alternative to improve the penetration rate of shaft construction. However, 
complete simultaneous operations of shaft drilling and pregrouting is not applicable because of inevitable interferences that may cause severe adverse impact on safety. First, the arrangement of drilling equipment for pregrouting holes might collide with that of shaft drilling. On the other hand, the grouts injected may penetrate into the drilled shaft, resulting in excessive levels of deformation, fracturing, and even collapse of the shaft wall and lining. Therefore, speeding up the sinking rate should be focused on conducting some of these operations simultaneously rather than the complete simultaneous operations.

The crucial concern of simultaneous operations is the commencement time of shaft drilling. In principle, the earlier the shaft drilling is started, the higher the improved sinking rate is. For the safety of the shaft wall and lining, a tight barrier which can protect against the damages caused by the increased groundwater pressure should be established in advance. In fact, injected formations with low permeability can act as such a barrier. Therefore, the pregrouting in the bedrock are divided into two stages, namely, pregrouting in the upper bedrock using straight holes and pregrouting in the lower bedrock using $S$-shaped holes. The injected upper bedrock as a tight cover is just the barrier to stop the increase of groundwater pressure and over-penetration of grouts. During simultaneous operations, the pregrouting for the upper bedrock (for this case, from $502 \mathrm{~m}$ to $665 \mathrm{~m}$ ) using straight grouting holes is conducted first, as shown in Figure 3(a). After completion of pregrouting for the upper bedrock, pregrouting for the lower bedrock (from $665 \mathrm{~m}$ to $1078 \mathrm{~m}$ ) using $S$-shaped holes and shaft drilling is started to be conducted simultaneously, i.e., the commencement of simultaneous operations, as shown in Figure 3(b). Until the simultaneous operations of shaft drilling and pregrouting in the lower bedrock are completed, the permanent steel headframe is setup and the bedrock is excavated by the conventional D\&B method, as shown in Figure 3(c). As the construction time of shaft drilling is often slightly longer than that of pregrouting in the lower bedrock, the saved construction time is that of the simultaneous operations, which also equals to the time for pregrouting in the lower bedrock using $S$-shaped holes. Increased sinking rate usually depends on the thickness of the lower bedrock and depth of the shaft.

\section{Technical Challenges and Solutions}

4.1. Stability of Grouting Holes. The stability of the unlined borehole is often considerably vulnerable. It may be affected by many factors, including the ground vibration. Compared with conducting pregrouting individually, shaft drillinginduced ground vibration becomes an adverse factor that might considerably deteriorate the stability of the borehole. Therefore, there is a need to assess the effect of ground vibration on the stability of grouting holes and thus to take appropriate solutions to protect these holes. The ground vibration can be excited by many man-made sources of vibration, including construction actives (e.g., explosive blasting and pile driving), machines, hammers, and traffic loading [20]. During drilling, the rotation of bit and drilling string becomes the specific source of vibration [12, 19]. Ground vibration will propagate through the ground in a form of seismic wave [11], which may cause stability issues of structure in vicinity [21]. Mechanized construction activities including using TBM and SBM virtually have an adverse effect on the environment [27]. It is reported that the stability and safety of some sensitive structures such as the historic buildings and foundations might still be deteriorated by the TBM/SBM tunnelling-induced ground vibration [28]. During the simultaneous operation of pregrouting and shaft drilling, the grouting holes are actually arranged in vicinity of the shaft. In this case, the stability of grouting holes might be affected by near-field vibration propagated from the drilled shaft.

The effect of ground vibration on nearby structures and facilities is usually characterized by the peak particle velocity (PPV) and corresponding dominant frequency [21]. As the magnitudes of the wave are always measured in forms of compressional wave $\mathrm{PPV}_{x}$, horizontal wave $\mathrm{PPV}_{y}$, and transverse wave $\mathrm{PPV}_{z}$, the PPV can be described as in the following equation [29].

$$
\mathrm{PPV}=\sqrt{\left(\mathrm{PPV}_{x}\right)^{2}+\left(\mathrm{PPV}_{y}\right)^{2}+\left(\mathrm{PPV}_{z}\right)^{2}}
$$

The propagation of ground vibration in ground largely depends on the source frequency and the damping properties of local ground materials. A lot of investigations reveal that the attenuation of velocity amplitudes strongly follows a power law $[20,28,30,31]$. As both the TBM-induced vibration and SBM-induced vibration are originated from the rotation of cutting wheel, the propagation of TBM tunnelling-induced vibration is employed to assess the vibration in vicinity of the drilled shaft in this work. Following Speakman and Lyons [31] and Grund et al. [28], the attenuation of PPV can be expressed as

$$
\mathrm{PPV}=\frac{K}{d} e^{-\alpha d},
$$

where $K$ and $\alpha$ are the constant parameters associated with the site and machine, and $d$ is the distance from the source in meters. The values of $K$ and $\alpha$ can be determined from the measured velocities at various distances by

$$
\begin{aligned}
\alpha & =\frac{-\ln \left(v_{2} d_{2} / v_{1} d_{1}\right)}{d_{2}-d_{1}}, \\
K & =\frac{v_{1} d_{1}}{e^{-\alpha d_{1}}},
\end{aligned}
$$

in which $v_{1}$ and $v_{2}$ are the measured values of PPV at distances $d_{1}$ and $d_{2}$, respectively. Therefore, the propagation of the seismic wave induced by shaft drilling can be illustrated in Figure 4. At the axis of the grouting hole, the distance from the vibration source increases with the depth counted from the origin of the coordinate (i.e., point of $O^{\prime}$ ). In this case, the maximum PPV in the grouting hole can be found at the origin point of $O^{\prime}$, and the stability of the grouting hole at the origin point of $O^{\prime}$ could be most seriously deteriorated. In principle, the interval between the 


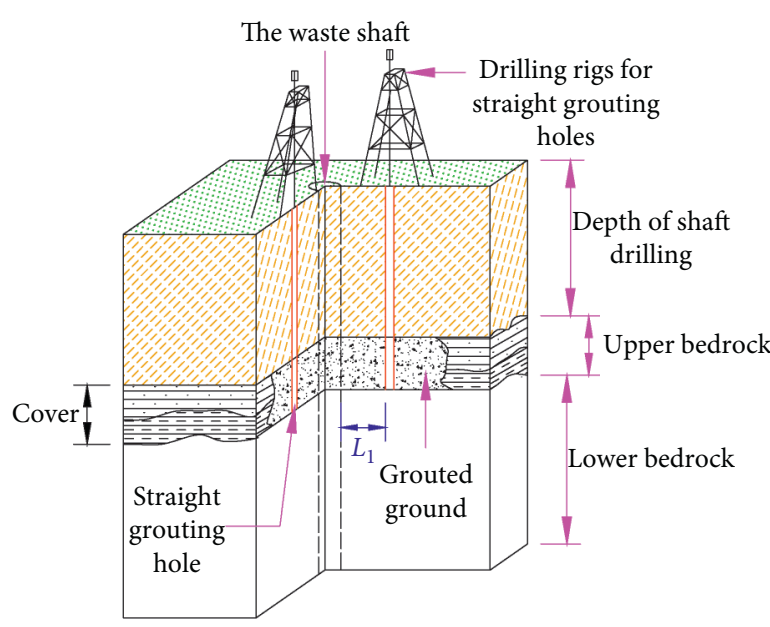

(a)

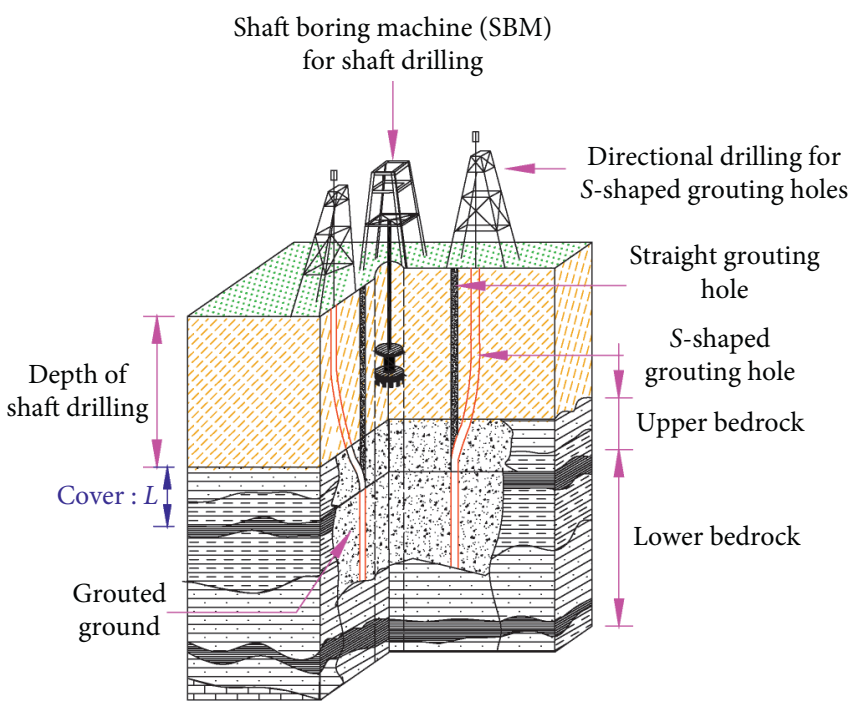

(b)

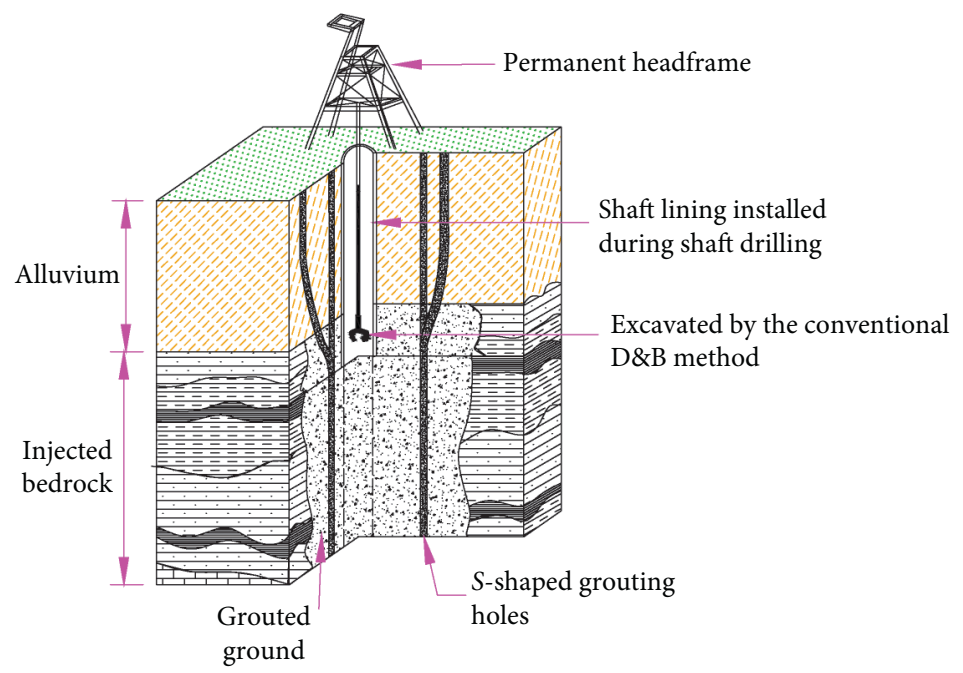

(c)

Figure 3: Schematic map of the simultaneous operations. (a) Pregrouting for the upper bedrock. (b) Pregrouting for the lower bedrock during the simultaneous operations. (c) Bedrock is excavated by the conventional D\&B method.

drilled shaft and grouting hole should be predefined at a large distance to avoid the possible disturbance caused by the ground vibration.

Many field testing and measurements investigated the ground vibration induced by the rotating of cutting wheel. For tunnelling using TBM with a diameter of about $7 \mathrm{~m}$, the maxima of PPV at a distance of $62 \mathrm{~m}$ is about $0.25 \mathrm{~mm} / \mathrm{s}$, while measured frequency mostly ranges from $10 \mathrm{~Hz}$ to $30 \mathrm{~Hz}$ [30]. In this case, at the distance of less than $3 \mathrm{~m}$ from the TBM, the structures might be very sensitive to the ground vibration induced by tunnelling and be deteriorated to some extent. Grund et al. [28] conducted an investigation on ground vibration induced by TBM with a diameter of $9.3 \mathrm{~m}$ and informed that monitored frequency content varied from $5 \mathrm{~Hz}$ to $80 \mathrm{~Hz}$, while the induced ground motion cannot be detected until at the distance of about $250 \mathrm{~m}$. Speakman and Lyons [31] reported the modelling results of

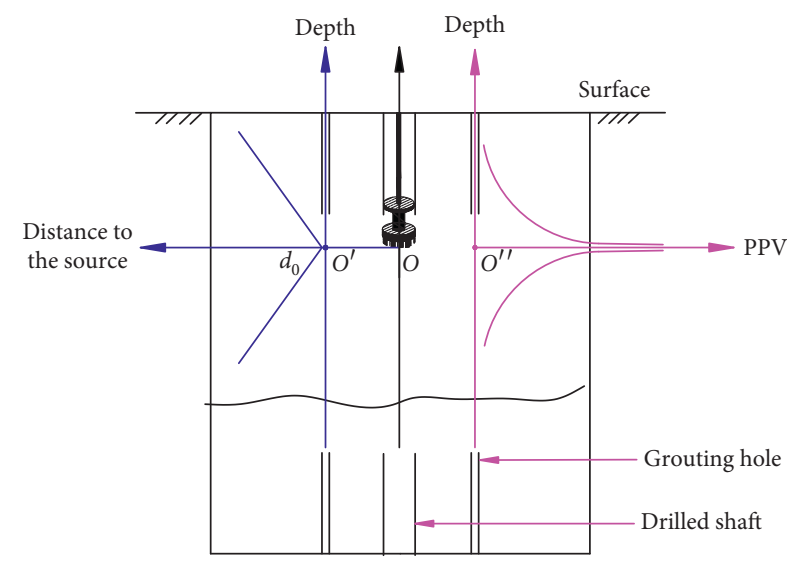

FIGURE 4: The vibration induced by shaft drilling. 
ground vibration induced by a 12.4 diameter TBM and indicated that the vibration from TBM varied from $10 \mathrm{~Hz}$ to $100 \mathrm{~Hz}$, and the influential range reached up to $100 \mathrm{~m}$. Yang [32] conducted numerical analysis using FlAC3D to understand the ground vibration caused by TBM and found that the influential range is about 6 times diameter of the tunnel. It could be deduced that in this case, the coverage of ground vibration induced by cutting wheel with $7 \mathrm{~m}$ diameter is believed to be greater than $50 \mathrm{~m}$.

Determination of a sufficient interval between the grouting hole and drilled shaft should be the simplest method to avoid the adverse effect of ground vibration on the stability of the unlined grouting hole. However, the interval cannot be excessively large because of technical limitations. First of all, the limit of build-rate of directional drilling is usually $6-8^{\circ} / 30 \mathrm{~m}[33,34]$. Accordingly, in directional drilling, for a horizontal interval of about $50 \mathrm{~m}$, the minimum length of $S$-shaped grouting holes to be directionally drilled will be up to $300 \mathrm{~m}$. Obviously, it is not costefficient. On the other hand, engineering experiences reveal that reliable thickness of water control curtain formed by grouting should range from $10 \mathrm{~m}$ to $20 \mathrm{~m}$. Accordingly, the grouting holes should be spaced at a distance of 5-10 $\mathrm{m}$ from the shaft wall if the penetration of grouts is predefined at $5-10 \mathrm{~m}$. The relationship of grouting range and coverage of ground vibration is shown in Figure 5. It can be evidently found that grouting holes will be located in coverage of the shaft drilling-induced ground vibration.

On the other hand, the origin of $S$-shaped grouting holes should be arranged outside of the coverage of shaft drilling because of safety. Meanwhile, the $S$-shaped grouting holes on the surface should be arranged near the shaft wall as close as possible to reduce cost of directional drilling. In this case, the maximum dimension of the SBM on the surface is about $20 \mathrm{~m}$, and the space available for shaft drilling operation is predefined at least $8 \mathrm{~m}$. Considering a $2 \mathrm{~m}$ safety interval, the origin of $S$-shaped grouting holes should be spaced at least at a distance of $20 \mathrm{~m}$ from the center of the shaft, as shown in Figure 6.

During simultaneous operations, the $S$-shaped grouting holes virtually fall in the coverage of ground vibration. Therefore, the adverse effect of ground vibration on stability of grouting holes cannot be avoided via a sufficient interval. For safety, the $S$-shaped grouting holes should be protected by specific solutions.

As known, casing is often considered as the most costeffective solution to ensure the stability and safety of drilling [35]. Normally, the borehole is just cased with steel tubes in unstable soil formations and fractured rocks. In order to address the adverse impact of ground vibration on the grouting hole during the simultaneous operations, the casing of $S$-shaped grouting holes was extended from the bottom of soil formations (at depth of $470 \mathrm{~m}$ ) into the initial point in the bedrock to be grouted (at depth of $645 \mathrm{~m}$ ). In other words, the $S$-shaped holes were completely formed in both soil formations and the upper bedrock (the cover) to resist interferences caused by shaft drilling-induced ground vibration.

For general purpose of the practical application of the new simultaneous operation method, the effect of ground

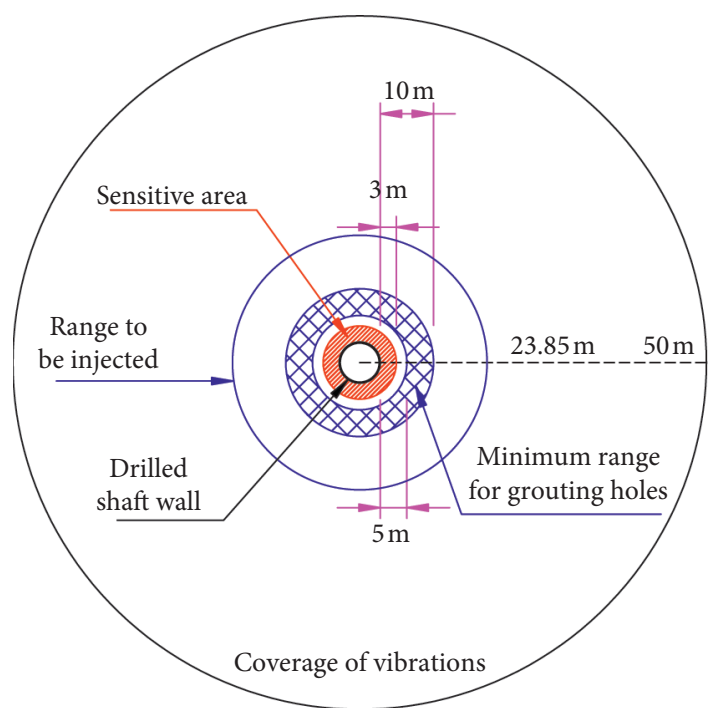

FIgURE 5: Relationship between the grouting range and coverage of vibration.

vibration on the stability of drilling in the vicinity could be evaluated appropriately. The coverage of the ground motion caused by shaft drilling can be approximately estimated using the results of TBM works conducted under similar conditions. The magnitude of the effect of ground vibration could be determined by the relative coordinates of the grouting hole and the drilled shaft. If the ground motion near the grouting hole cannot be neglected, protective measures such as the casing or ground improvement should be applied to ensure the stability of grouting holes. Moreover, the ground vibration caused by the rotating of the big cutting wheel of the SBM still deserves further investigation by using both the detailed field testing and theoretical analysis because the ground motion caused by the vertical drilling of SBM might differ from that caused by the horizontal drilling such as drilling using TBM.

4.2. Safety of the Drilled Shaft Wall. During pregrouting, the groundwater pressure in vicinity of the grouting hole will be increased, and the grouts might also over penetrate to the drilled shaft. During simultaneous operations, the injected upper bedrock acting as a tight cover is expected to stop the uncontrolled over-travelling of grouts from $S$-shaped grouting holes. However, the groundwater pressure may still be increased to some extent because of grouting. The increased groundwater pressure in vicinity of the drilled shaft might deteriorate the safety of the shaft wall. The process of grouting can be considered as the displacement of groundwater by grouts, which inevitably causes the increase of groundwater pressure in a certain range [36]. Although the grouts might not crossover the tight cover, the water as a Newtonian fluid with low viscosity could travel through the cover and thus increase the groundwater pressure above the cover which is in vicinity of the drilled shaft. In this case, the loading acting on the shaft wall will be increased, and thus, the stability of walls might be further deteriorated. In principle, the extra loading largely depends on the 


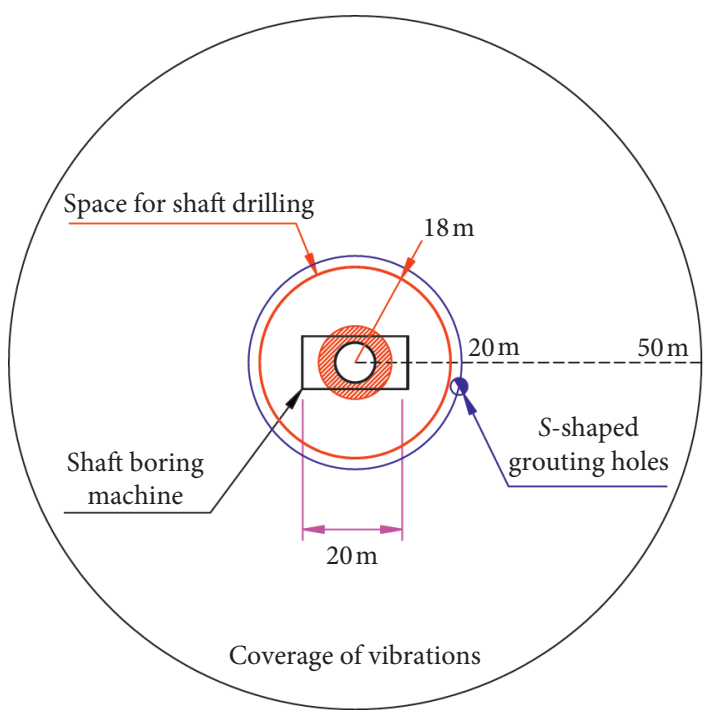

(a)

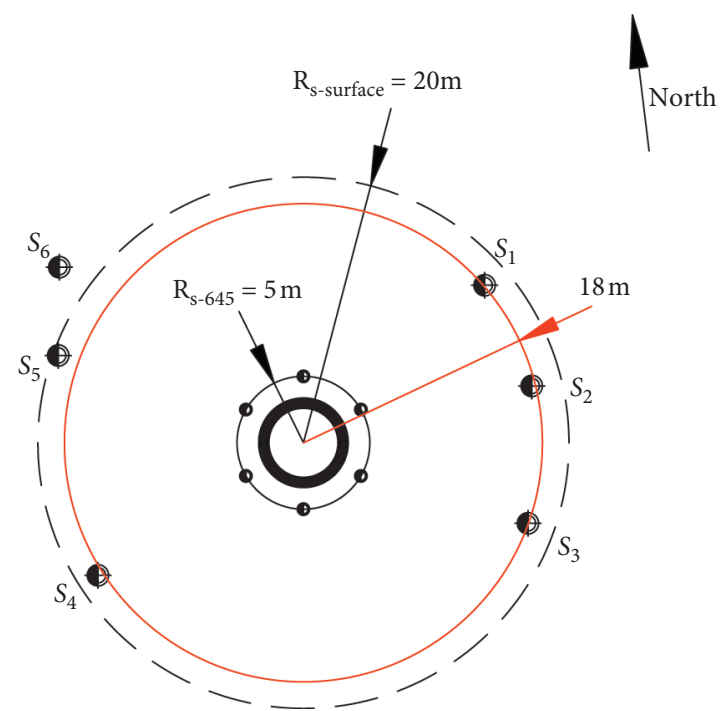

(b)

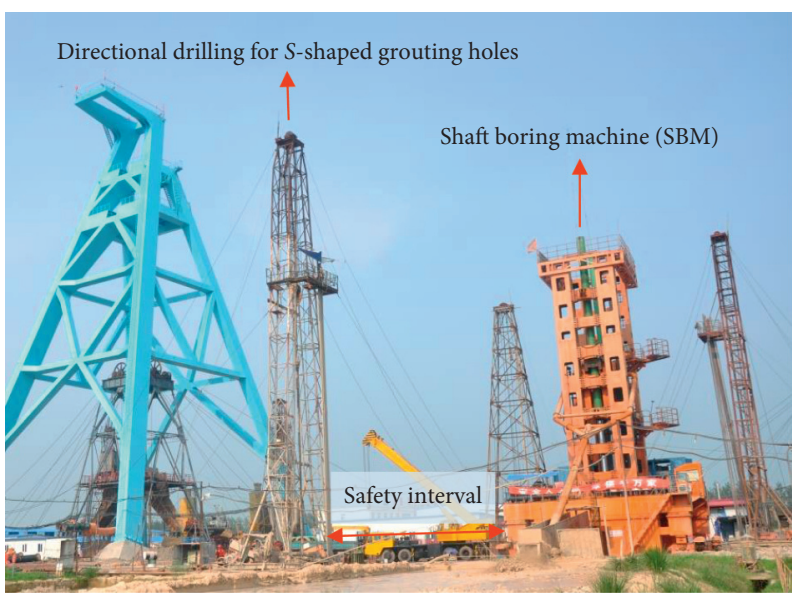

(c)

Figure 6: Layout of $S$-shaped grouting holes during simultaneous operations. (a) Grouting holes spaced outside the SBM. (b) Layout of grouting holes on the surface. (c) Equipment arrangement on the surface.

permeability and thickness of the cover. To minimize the effect of increased groundwater pressure, the greater the thickness of cover (i.e., length of the upper bedrock) is predefined, the lower the permeability of cover after grouting will be. However, a greater thickness of the cover will lead to a smaller length of the lower bedrock which would reduce the time of simultaneous operations, and oversmall thickness of the cover will result in a high impermeability of the cover which could considerably increase the cost of grouting for the cover. Therefore, a balance between the thickness and impermeability of the cover should be appropriately determined, to ensure the safety of the shaft wall.

The grouting-induced upward flow can be considered as grouting using water from the bottom of the cover. Considering the homogeneity of the cover after grouting, the spherical penetration of water flow can be evaluated using
Maag's solution $[37,38]$. The penetration length of induced water flow can be determined by

$$
\begin{aligned}
R_{0} & =\sqrt[3]{\frac{3 K t \Delta P r_{0}}{\beta n}}, \\
\beta & =\frac{\mu_{g}}{\mu_{w}},
\end{aligned}
$$

where $R_{0}$ is the penetration length, $k$ is the hydraulic conductivity of cover after injection, $t$ is the grouting time, $\Delta P$ is the grouting pressure, $r_{0}$ is the radius of grouting hole, $n$ is the porosity of the cover, and $\mu_{q}$ and $\mu_{w}$ are the viscosities of grout and water, respectively. During estimating the penetration length $R_{0}$, the hydraulic conductivity $k$ can be appropriately predefined based on the qualified permeability of the cover after grouting. According to the Chinese 
standard [39], required residual water inflow of the cover can be predefined at $3 \mathrm{~m}^{3} / \mathrm{d}$. Therefore, the hydraulic conductivity $k$ can be estimated using

$$
Q_{1}=1.366 \frac{k M\left(2 H_{0}-M\right)}{\log R-\log r^{\prime}},
$$

where $Q_{1}$ is the residual water inflow, i.e., $3 \mathrm{~m}^{3} / \mathrm{d}, k$ is the hydraulic conductivity, $H_{0}$ is the height from the groundwater table to bottom of the lowest aquifer, $M$ is the total thickness of the aquifer, $r^{\prime}$ is the excavated radius of the shaft, and $R$ is the radius of influence which can be empirically estimated by

$$
R=10 S_{w} \sqrt{k}
$$

where $S_{w}$ is the maximum drawdown of groundwater table during shaft excavation.

Considering the deviation of above estimation from the site, a safety interval should be taken into account to determine the length of the cover. Hence, the length of the cover should be no less than the sum of estimated penetration length $R_{0}$ and the safety interval. The safety interval might not be less than 10 meters according to experiences of pregrouting from the surface. What should be noted is that the permeability of the cover after grouting must be examined by the water injection test to confirm whether the hydraulic conductivity of the cover has met the predefined value $k$. If not, the cover might not be tight adequately, and thus, repeated grouting operations will be conducted to further improve the impermeability of the cover. For this case, the length of the cover is predetermined at $120 \mathrm{~m}$, accounting for about $22.5 \%$ of the bedrock to be grouted, as shown in Figure 7. During the simultaneous operations, damages of the drilled shaft wall caused by over-penetrated grouts and extra groundwater pressure were not observed, which confirmed the reliability of the cover to protect the drilled shaft.

4.3. Resource Recycling of Waste Drilling Mud. During the simultaneous operations, a huge volume of waste drilling mud will be produced, and usually, it is stored in a pond for further harmless treatment. Traditionally, the treatment methods include harmlessly treating and reutilization as some renewable materials. Undoubtedly, resource recycling should be the most cost-effective method. Although a lot of attentions had been focused on conversion of the waste mud to cement materials in petroleum and gas industries in recent years [19], converting the waste drilling mud to available grouting materials is still rarely reported and an innovative attempt. For pregrouting in Chinese coal mine, there is always a large demand of man-made clay slurry to prepare the claycement (Cl-C) grouts. The huge volume of waste drilling mud produced in simultaneous operations provides a

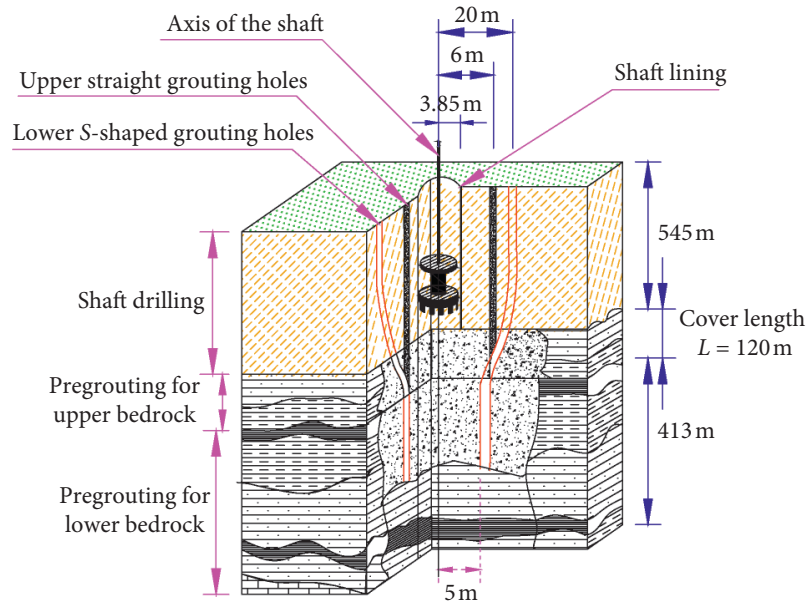

Figure 7: Arrangement of straight holes and $s$-shaped holes.

good opportunity to try to reuse the waste mud as grouting materials. The previous experimental investigation has confirmed the feasibility of reusing the waste drilling mud to prepare the $\mathrm{Cl}-\mathrm{C}$ grouts [40]. In this work, the modified water drilling mud is utilized to prepare qualified $\mathrm{Cl}-\mathrm{C}$ grouts on the site to examine the reliability of reusing the waste mud as grouting materials.

For this case, the waste drilling mud consists of cohesive soils and water, with 0.1 wt $\%$ sodium tripolyphosphate (STPP) as the chemical additive. Based on experimentally investigation, the viscosity of waste drilling mud before preparing the $\mathrm{Cl}-\mathrm{C}$ grouts should be reduced to an acceptable level [40]. There are two available methods to reduce the viscosity. One is addition of chemical agents, saying calcium chloride $\left(\mathrm{CaCl}_{2}\right)$. Another is dilution with fresh water which is much more economical. It should be noted that the addition of chemical additives might be prior to using water, if the density of waste drilling mud is relatively low. The viscosity and density of the waste drilling mud after treatment should meet the technical requirement of $\mathrm{Cl}-\mathrm{C}$ grouts according to the Chinese standard [39], as illustrated in Table 2.

In this case, the excessive viscosity of waste drilling mud is reduced with fresh water, and then, the qualified mud is stored in a slurry pond, as shown in Figure 8. Then, cement is mixed with the waste mud with $5 \mathrm{~min}$ agitation at $1000 \mathrm{rpm}$ to avoid the formation of lumps, and after that, the glass water as additive is added into the mixture and stirred for another $5 \mathrm{~min}$ to achieve a uniform mixture. The properties of grouts should be examined and recorded before injection. The grouts should be adjusted timely according to the variations of grouting pressure and injected volume of grouts. During simultaneous operations, about one-third of the waste drilling mud (i.e., about $15,000 \mathrm{~m}^{3}$ ) is utilized to prepare Cl-C-like grouts (about $15,900 \mathrm{~m}^{3}$ grouts). The grouting quality is considerably excellent, with a measured residual water inflow of only $0.4 \mathrm{~m}^{3}$. 
TABle 2: Technical requirements of $\mathrm{Cl}-\mathrm{C}$ grout and the clay slurry.

\begin{tabular}{|c|c|c|c|c|c|c|c|}
\hline \multicolumn{4}{|c|}{ Mixing proportion } & \multicolumn{4}{|c|}{ Qualified Cl-C grout } \\
\hline $\begin{array}{l}\text { Cement } \\
\text { content }\end{array}$ & $\begin{array}{l}\text { Dosage of water } \\
\text { glass }\end{array}$ & $\begin{array}{l}\text { Density of clay } \\
\text { slurry }\end{array}$ & $\begin{array}{l}\text { Initial funnel viscosity of } \\
\text { clay slurry }\end{array}$ & Density & $\begin{array}{l}\text { Sands } \\
\text { content }\end{array}$ & Bleeding & $\begin{array}{l}\text { Initial funnel } \\
\text { viscosity }\end{array}$ \\
\hline $\begin{array}{l}100-300 \mathrm{~kg} / \\
\mathrm{m}^{3}\end{array}$ & $10-30 \mathrm{~L} / \mathrm{m}^{3}$ & $1.12-1.24 \mathrm{~g} / \mathrm{cm}^{3}$ & $<20 \mathrm{~s}$ & $\begin{array}{c}1.20-1.35 \mathrm{~g} / \\
\mathrm{cm}^{3}\end{array}$ & $<5 \%$ & $<5 \%$ & $50 s-80 s$ \\
\hline
\end{tabular}

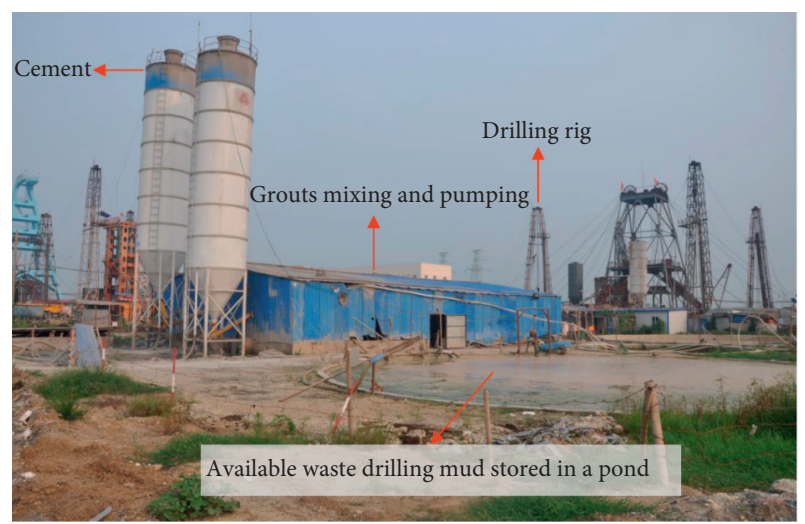

FIGURE 8: Grouting using the waste drilling mud.

It should be noted that because of the deviations of geological conditions and differences in shaft drilling operations, the properties of the waste mud and behavior of $\mathrm{Cl}$ C-like grouts prepared using the waste mud should be experimentally investigated before reutilizing this material in other cases. Additives used to modify the waste mud and the proportioning of the $\mathrm{Cl}$-C-like grouts might be not the same for all cases.

\section{Conclusions}

The practical experience has revealed that the innovative simultaneous operations of shaft drilling and pregrouting could considerably improve the sinking rate of the shaft. For the waste shaft involved in this work (with a depth of about $1068 \mathrm{~m}$ ), which would be excavated by conventional step-bystep construction procedure, the estimated construction time might be up to 35 months. After application of the proposed method in this case, the saved construction time for the shaft sinking is about 12 months, accounting for about $34 \%$ of the estimated total time of the shaft construction under the conventional sinking procedure. There was no accident event encountered during the simultaneous operations. It means the construction time using the simultaneous operation method is just $66 \%$ of that of the traditional excavation method. The proposed method could virtually improve the shaft sinking rate and save the construction cost.

To conduct this simultaneous operation of shaft drilling and pregrouting, the crucial technique is to reasonably determine the spatial locations of both the drilled shaft and grouting holes, as well as the start time of each construction work. In most cases, the simultaneous operation is applicable to other shaft construction projects as long as the spatial and time relationships between the pregrouting operation and the shaft drilling are properly addressed. To perform the proposed simultaneous operation method, the pregrouting using straight holes must be conducted first. After that, shaft drilling and pregrouting using $S$-shaped holes can be carried out simultaneously. The shaft drilling is executed in the upper formations, while the pregrouting using $S$-shaped holes is performed in the lower bedrocks. Technical challenges on stability of grouting holes and safety of shaft unlined wall should be appropriately addressed in advance, to perform the simultaneous operation smoothly. In practices, the range of shaft drilling-induced ground vibration which might deteriorate the stability of grouting holes could be evaluated according to the penetration of ground vibration caused by TBM tunnelling. The ground motion caused by shaft drilling can be characterized by the value of PPV in the ground, which usually attenuates with the distance to the rotating cutting wheel in exponential law. The nearest the position to the rotating bit of the SBM is, the higher the residual ground vibration will be. If the grouting hole is in the range of ground vibration, protective measures including casing and ground improvement should be applied to ensure the stability of grouting holes. In this case, estimated coverage of the ground vibration induced by shaft drilling with a $7.7 \mathrm{~m}$ cutting bit will be greater than $50 \mathrm{~m}$, and the grouting holes during the simultaneous operations will fall in range of the coverage. Accordingly, the grouting holes were protected by full casing to avoid deterioration in stability or even collapse.

As the groundwater pressure in the vicinity of the drilled shaft can be enhanced by the grouting activities which are being operated in lower formations, the stability of unlined walls of the drilled shaft is achieved by a tight cover between the drilled shaft and the pregrouting holes. The cover is actually injected horizontal formations with sufficient thickness and impermeability, which can considerably reduce or even completely stop the increased groundwater pressure in vicinity of the drilled shaft. The thickness and permeability of the cover could be determined using the spherical penetration of water flow from the bottom of the cover, on the basis of Maag's solution. On the other hand, after proper modifications, the waste drilling mud can be reutilized to prepare clay-cement-like grouts, which could provide an economical and environment-friendly solution to harmlessly treat the huge volume of waste drilling mud in a resource recycling way. Because of uncertainties of geology in various projects, the properties of waste drilling mud and behaviors of grouts 
prepared using the waste mud should be experimentally investigated before reutilization to ensure the quality of grouts. In this case, the thickness of the cover is defined at $120 \mathrm{~m}$ (i.e., it is also the length of straight grouting holes), and the waste drilling mud is modified with the addition of fresh water to reduce its viscosity. The measured residual water inflow of the whole shaft is only $0.4 \mathrm{~m}^{3}$, implying a very good grouting quality for groundwater control.

Although the proposed solutions for the technical challenges emerged during the simultaneous operations might be conservative to some extent, the accuracy is still acceptable for smoothly implementing the simultaneous operations in practices. As of now, the simultaneous operations technique has served for more than 5 shafts in Chinese coal mines. Proposed principles can effectively deal with these technical challenges, and the economic and social benefits have evidently supported the reliability of the innovative construction technique and can virtually speed up the shaft sinking rate.

\section{Data Availability}

The data used to support the findings of this study are included within the article.

\section{Conflicts of Interest}

The authors declare that there are no conflicts of interest.

\section{Acknowledgments}

The authors are grateful for the financial support from the National Key Technology R\&D Program of China (2008BAB33B02).

\section{References}

[1] M. Cao, H. Liang, D. Fan, Y. Wang, H. Jiang, and N. Sun, "Ultrasonic logging instrument for shaft sinking by drilling," Measurement, vol. 132, pp. 344-349, 2019.

[2] A. Lashgari, M. M. Fouladgar, A. Yazdani-Chamzini, and M. J. Skibniewski, "Using an integrated model for shaft sinking method selection/kompleksinio modelio naudojimas gręžinių irengimo metodui parinkti," Journal of Civil Engineering and Management, vol. 17, no. 4, pp. 569-580, 2011.

[3] Z. Liu, "Development and prospect of mechanical shaft boring technology," Journal of China Coal Society, vol. 38, pp. 1116-1122, 2013, in Chinese.

[4] H. K. O. Dietz, "Aspects of advanced grouting during shaft sinking in South Africa," International Journal of Mine Water, vol. 1, no. 2, pp. 19-28, 1982.

[5] E. Dorn and O. Kaledin, "Modern and innovative shaft sinking and construction technology with examples from current projects/moderne und innovative schachtbautechnik am beispiel aktueller abteufprojekte," Geomechanics and Tunnelling, vol. 6, no. 5, pp. 574-581, 2013.

[6] E. J. Kipko, J. A. Polozov, V. A. Lagunov, and O. J. Lushnikova, "Experience in sealing water bearing strata during deep shaft sinking," International Journal of Mine Water, vol. 3, no. 4, pp. 55-62, 1984.
[7] B. Tang, H. Cheng, Y. Tang et al., "Experiences of gripper TBM application in shaft coal mine: a case study in zhangji coal mine, China," Tunnelling and Underground Space Technology, vol. 81, pp. 660-668, 2018.

[8] Z. Xu, C. Liu, X. Zhou, G. Gao, and X. Feng, "Full-scale physical modelling of fissure grouting in deep underground rocks," Tunnelling and Underground Space Technology, vol. 89, pp. 249-261, 2019.

[9] C. Yang and Z. Wang, "Surface pre-grouting and freezing for shaft sinking in aquifer formations," Mine Water and the Environment, vol. 24, no. 4, pp. 209-212, 2005.

[10] Z. Kristafor, Chapter 5 Simultaneous Operations, Risk Analysis for Prevention of Hazardous Situations in Petroleum and Natural Gas Engineering, pp. 96-114, IGI Group, Hershey, PA, USA, 2014.

[11] D. Ainalis, L. Ducarne, O. Kaufmann, J.-P. Tshibangu, O. Verlinden, and G. Kouroussis, "Improved analysis of ground vibrations produced by man-made sources," Science of The Total Environment, vol. 616, pp. 517-530, 2018.

[12] A. A. Ibrahim, T. A. Musa, and A. M. Fadoul, "Drilling mechanics: consequences and relevance of drill string vibration on wellbore stability," Journal of Applied Sciences, vol. 4, pp. 106-109, 2004.

[13] J. J. Bailey and I. Finnie, "An analytical study of drill-string vibration," Journal of Engineering for Industry, vol. 82, 1960.

[14] I. Finnie and J. J. Bailey, "An experimental study of drill-string vibration," Journal of Engineering for Industry, vol. 82, 1960.

[15] A. Kyllingstad and G. W. Halsey, "A study of slip/stick motion of the bit," SPE Drilling Engineering, vol. 3, no. 4, pp. 369-373, 1988.

[16] J. F. Brett, "The genesis of bit-induced torsional drillstring vibrations," SPE Drilling Engineering, vol. 7, no. 3, pp. 168-174, 1992.

[17] K.-I. Itakura, K. Sato, G. Deguchi, Y. Ichihara, H. Matsumoto, and H. Eguchi, "Development of a roof-logging system by rockbolt drilling," Mining Technology IMM Transactions Section A, vol. 106, pp. A118-A123, 1997.

[18] S. Liu, Y. Feng, and D. Liu, "Numerical experiments of dynamic response characteristics of rock drilling on stratified roof in coal roadway," Chinese Journal of Rock Mechanics and Engineering, vol. 33, pp. 3170-3176, 2014.

[19] S. Liu, M. Fu, H. Jia, W. Li, and Y. Luo, "Numerical simulation and analysis of drill rods vibration during roof bolt hole drilling in underground mines," International Journal of Mining Science and Technology, vol. 28, no. 6, pp. 877-884, 2018.

[20] L. Auersch and S. Said, "Attenuation of ground vibrations due to different technical sources," Earthquake Engineering and Engineering Vibration, vol. 9, no. 3, pp. 337-344, 2010.

[21] O. Tavasoli and M. Ghazavi, "Wave propagation and ground vibrations due to non-uniform cross-sections piles driving," Computers and Geotechnics, vol. 104, pp. 13-21, 2018.

[22] R. Widmann, "International society for rock mechanics on grouting," International Journal of Rock Mechanics and Mining Sciences \& Geomechanics Abstracts, vol. 33, p. 45, 1996.

[23] S. A. Leonard and J. A. Stegemann, "Stabilization/solidification of petroleum drill cuttings," Journal of Hazardous Materials, vol. 174, no. 1-3, pp. 463-472, 2010.

[24] X. Zha, X. Liao, X. Zhao, F. Liu, A. Q. He, and W. X. Xiong, "Turning waste drilling fluids into a new, sustainable soil resources for landscaping," Ecological Engineering, vol. 121, pp. 130-136, 2018. 
[25] A. S. Ball, R. J. Stewart, and K. Schliephake, "A review of the current options for the treatment and safe disposal of drill cuttings," Waste Management \& Research, vol. 30, no. 5, pp. 457-473, 2012.

[26] D. Arditi and H. M. Gunaydin, "Total quality management in the construction process," International Journal of Project Management, vol. 15, no. 4, pp. 235-243, 1997.

[27] D. M. Hiller and V. S. Hope, "Groundborne vibration generated by mechanized construction activities," Proceedings of the Institution of Civil Engineers-Geotechnical Engineering, vol. 131, no. 4, pp. 223-232, 1998.

[28] M. Grund, J. R. R. Ritter, and M. Gehrig, "Ground motion relations while TBM drilling in unconsolidated sediments," Rock Mechanics and Rock Engineering, vol. 49, no. 5, pp. 1773-1787, 2016.

[29] K. E. Vogiatzis and G. Kouroussis, "Environmental groundborne noise and vibration from urban light rail transportation during construction and operation," Current Pollution Reports, vol. 3, no. 2, pp. 162-173, 2017.

[30] R. F. Flanagan, "Ground vibration from TBMs and shields," Tunnels and Tunnelling International, vol. 25, pp. 30-33, 1993.

[31] C. Speakman and S. Lyons, "Tunnelling induced groundborne noise modelling, acoustics 2009: research to consulting," in Proceedings of the Annual Conference of the Australian Acoustical Society, pp. 1-5, Adelaide, Australia, 2009.

[32] L. Yang, Analysis of Vibration Effect and Surface Settlement Induced by TBM Excavating Subway Tunnel in Urban Area, Shanghai Jiao Tong University, Shanghai, China, 2013, in Chinese.

[33] I. J. Inyang and J. F. Whidborne, "Bilinear modelling, control and stability of directional drilling," Control Engineering Practice, vol. 82, pp. 161-172, 2019.

[34] L. Wang, B. Zhou, Q. Li, X. Su, L. Zhang, and X. Teng, "Application of rotary geo-steering technology with high build-up rate in hadson oilfeld," Oil Drilling \& Production Technology, vol. 37, pp. 23-27, 2015.

[35] D. Patel, V. Thakar, S. Pandian, M. Shah, and A. Sircar, "A review on casing while drilling technology for oil and gas production with well control model and economical analysis," Petroleum, vol. 5, no. 1, pp. 1-12, 2019.

[36] L. Zou, U. Håkansson, and V. Cvetkovic, "Two-phase cement grout propagation in homogeneous water-saturated rock fractures," International Journal of Rock Mechanics and Mining Sciences, vol. 106, pp. 243-249, 2018.

[37] Z. Hao, B. Lin, Y. Gao, and Y. Cheng, "Establishment and application of drilling sealing model in the spherical grouting mode based on the loosing-circle theory," International Journal of Mining Science and Technology, vol. 22, no. 6, pp. 895-898, 2012.

[38] E. Maag, Ueber die Verfestigung und Dichtung des Baugrundes (Injektionen): Course on Soil Mech, Zurich International School, Zurich, Switzerland, 1938.

[39] China Planning Press, Code for Construction of Shaft and Roadway of Coal Mine: GB50511-2010, pp. 18-38, China Planning Press, Beijing, China, 2011, in Chinese.

[40] Z. Chen, R. Xu, and G. Gao, "Research on waste drilling mud being used in grouting," Journal of China Coal Society, vol. 36, pp. 49-53, 2011. 